\section{Mapping malaria risk using \\ environmental and anthropic \\ variables}

\section{Mapeamento do risco de malaria utilizando variáveis ambientais e antrópicas}

\section{Mauricio Edilberto Rincón-Romero'}

\section{Julián Esteban Londoño"}

' Investigator Professor of Geomatics, Universidad del Valle, Colombia. Grupo de Investigación e Simulación y Modelación Dinámica Espacial - GISMODEL. Escuela de Ingeniería Civil y Geomática.

"Topographic Engineer, Universidad del Valle, Cali - Colombia.

\section{Abstract}

Despite much research in the identification of areas with malaria, it is urgent to further investigate mapping techniques to achieve better approaches in strategies to prevent, mitigate, and eradicate the mosquito and the illness eventually. By using spatial distributed modeling techniques with Geographical Information Systems (GIS), the study proposes methodology to map malaria risk zoning for the municipality of Buenaventura in Colombia. The model proposed by Craig et al. ${ }^{1}$ using climatic information was adapted to the conditions of the study area regarding scale and spatial resolution. Geomorphologic and anthropic variables were added to improve spatial allocation of areas with higher risk of contracting the illness, refining zoning. Then, they were contrasted with the locations reported by health entities ${ }^{2}$, taking into account spatial distribution. The comparison of results shows a decrease in the area obtained initially using the Craig et al. model ${ }^{1}$ (1999), from $5,422.4 \mathrm{~km}^{2}$ (89.1\% of the municipality's territory) to $624.3 \mathrm{~km}^{2}$ (approximately $10 \%$ of the municipality's area), yielding a total reduction of $78.8 \%$ when environmental and anthropic variables were included in the model. Data show that of the 9,863 cases reported during 2001 to 2005 for 20 selected towns as basis for the amount of surveyed malaria cases ${ }^{2}, 1,132$ were located in the very high-risk areas, 7,662 were in the areas of moderate risk, and 1,066 cases in low-risk areas, showing that $89 \%$ of the cases reported fell into the areas with higher risk for malaria.

Keywords: Malaria. GIS. Spatial modeling. Environmental modeling. Malaria risk zoning. 


\section{Resumen}

A pesar de muchas investigaciones en la identificación de las zonas con presencia de malaria, es urgente profundizar las técnicas de su mapeo para lograr mejores aproximaciones, para ayudar a focalizar los esfuerzos y recursos en prevención, mitigación y estrategias de erradicación del mosquito y eventualmente de la enfermedad. Usando modelación espacial distribuida con herramientas de Sistemas de Información Geográfica (SIG), el presente estudio propone una metodología para el mapeo y la zonificación del riesgo de malaria en el municipio de Buenaventura-Colombia. Se presenta una estrategia de adaptación del modelo propuesto por Craig et al. ${ }^{1}$ (1999) que usa información climática, adaptándolo a las condiciones propias del área de estudio en cuanto a escala y resolución espacial. Se adicionaron variables geomorfológicas y antrópicas para mejorar la localización espacial de las zonas con mayor riesgo de contraer la enfermedad, refinando la zonificación, y se contrastó espacialmente con los sitios reportados por las entidades de salud $^{2}$. La comparación de los resultados muestra la disminución del área que se obtuvo inicialmente con la aplicación del modelo de Craig et al. ${ }^{1}$ de $5422.4 \mathrm{~km}^{2}(89.1 \%$ del territorio del municipio) a $624.3 \mathrm{~km}^{2}$ (aproximadamente 10\% del área del municipio), dando una reducción total del $78.8 \%$ al incluir las variables ambientales y antrópicas en la producción del mapa de riesgo. Los datos muestran que de 9,860 casos reportados durante 2001 y 2005 para 20 localidades seleccionadas con base en la cantidad de registros de malaria ${ }^{2}, 1,132$ se ubicaron en las zonas identificadas de muy alto riesgo, 7,662 se sobrepusieron en las zonas de riesgo moderado y 1,066 casos en la zona de riesgo bajo, mostrando que el $89 \%$ de ellos se ubican en las zonas modeladas con mayor riesgo de malaria.

Palabras claves: Malaria. SIG. Modelación espacial. Modelación ambiental. Zonificación del riesgo de malaria.

\section{Introduction}

Spatial distribution of associated variables, as well as transmission intensity, have become an urgent need, especially in endemic areas ${ }^{3-12}$. This needs to be acknowledged to improve control and mitigation measures to fight against malaria. In this sense, cartography offers an understandable solution.

However, mapping spatial distribution of malaria is complex for many reasons: initially, available data from malaria illness registrations are limited ${ }^{6}$, and on occasions they have not been collected thoroughly. Regarding illness mapping methodologies, from the cartographic point of view two strategies can be distinguished: the simplest is representation in a choropleth map. The second one is a distribution of clouds of points of sample localization ${ }^{13}$. A choropleth map distinguishes administrative units with different colors to relate with its value samples ${ }^{3,11,12,14,16}$. In this case, it shows the number of people affected by the illness. This map representation is clearly very widespread and not very precise from the spatial distribution point of view. The second strategy is the detailed localization of each sample or survey, or of the event for mapping ${ }^{6,11,16}$. This is much more accurate from the location point of view. However, in cases where there are many points located in a nearest position, the identification point can be lost. In such case, we can use a convention representation instead.

At the moment, there are several tools available in the Geographical Information Systems (GIS) that facilitate malaria spatial representation through maps ${ }^{19,20}$. The methods that have been used for mapping the illness, vector, prevalent parasite, and affected areas are very diverse. Regions that suffer aggressively from the illness have allowed for very encompassing studies that involve several countries ${ }^{1,18}$. This is the case of MARA ${ }^{18}$, which have been operating in the African continent since the early 1990s. National politics in these countries have been able to increase knowledge on the conditions associated with the illness, transmitter 
vector, and possible epidemic conditions ${ }^{5}$. Regarding the same space scale, studies such as Sousa-Santos ${ }^{7}$ and Atanaka-Santos ${ }^{13}$ involve results for a broad area in the Amazonian region. Equally, statistical space models have made important findings in malaria risk spatial distribution ${ }^{7-13,20,21}$, and Bayesian geostatistical models are recognized as good tools for modeling the transmission of the risk of malaria ${ }^{22,23}$. They produce smoothed maps in many environmental cases by using correlations between variables.

Although known investigations have accurately determined the areas with favorable conditions for the transmission of the illness ${ }^{19,24-27}$, achievements produce vast extensions with high probability of illness presence $^{8,13}$. However, a systemic methodology has as yet not been formulated to integrate the different scale representation and the variables impacting the presence of the illness, vector or population affected. Additionally, it is necessary to approach space representation to provide information as basis to plan for activities to confront the illness ${ }^{16}$. In addition, the indicator used most recently to map malaria risk is the Annual Parasite Index (API). This index establishes a relationship between the total number of positive blood slides and the total population $^{7,12}$.

Although malaria has been implacable in Colombia, plans to control and mitigate the illness have not been executed with the required effectiveness. One of the main reasons - aside from the most obvious (reduced budgets for health investment) - is the lack of knowledge on the precise risk areas. Colombia is a tropical country with a diversity of climates and varied environmental conditions. Eighty-five percent of the Colombian territory has an altitude below 1,600m above sea level. These are the areas with greater occurrence of the illness. The said areas are inhabited by 24 million Colombians (65\% of the population) where they are more exposed to the illness ${ }^{28}$. The regions with greatest malaria risk in Colombia are the Pacific Coast, Urabá, the lowest area of the Cauca River basin, and the Sinú River basin.
The Ministry of Health in Colombia, in its National Plan to Control Malaria, has recently tried to combat malaria with campaigns based on timely diagnosis and treatment, vector selective control, enhanced surveillance within public health agencies, and participation of social sectors. These activities include mitigation measures by using mosquito netting and fostering social awareness through educational campaigns for the prevention of mosquito proliferation by reducing its hatcheries on stagnated waters. They also aim at improving health conditions in the vast regions where the presence of illness is known ${ }^{29}$.

The aim of this study is to develop a methodology for mapping malaria risk, which integrates physical variables such as temperature, precipitation and geomorphologic features with related aspect to human being, which in this study will be recognized as anthropic variables.

\section{Methods}

Mapping malaria riskinfection is presented cartographically as a product of spatial correlations of analyzed events using GIS tools. The proposal integrates environmental variables (temperature and precipitation) within Craig et al. model ${ }^{1}$ to identify climate convenience for malaria. Then, physical landscape variables are added, and later combined spatially with anthropic variables, including human features. The spatial structure used was raster with $100 \mathrm{~m}$ pixel size.

The exercise presented here was developed in three stages: 1) Characterization of the study area, compiling environmental, physical, and anthropic information; 2) adaptation and application of the model strategy in terms of scale and resolution, including data cleaning treatment for spatial distribution, parameterization and model refinement; 3 ) application of Craig et al. ${ }^{1}$ model to generate a Malaria Climatic Convenience Index (MCCI). In addition, we included natural variables to generate the Malaria Natural Convenience Index (MNCI), and finally the incorporation of an anthropogenic variable 
to the model to generate the Malaria Risk Transmission Index (MRTI). At the end, MRTI is compared with malaria cases reported in the area $^{2}$, in order to assess the model results.

\section{Characterization of the study area}

The study area is the municipality of Buenaventura in the Department (State) of Valle del Cauca, Colombia (Figure 1), located in the southwest Pacific region of the country. This municipality covers a surface area of $6,297 \mathrm{~km}^{2}$, extending to the Western mountain range of the Colombian Andes, with elevations reaching 2,800 m above sea level. This allows the study area to have a great diversity of environmental conditions, in addition to the prevailing climatic dynamics in this region of the globe. It has an average temperature of $25^{\circ} \mathrm{C}$ with higher temperatures in coastal areas, reaching $35^{\circ} \mathrm{C}$ and low temperatures around $11^{\circ} \mathrm{C}$ in the mountainous region. In the area, temperature conditions remain relatively constant during the whole year, but variations occur between day-time and night-time, with average changes around $8^{\circ} \mathrm{C}$ in the low coastal areas, and changes in the mountain areas reaching variations up to $12^{\circ} \mathrm{C}^{29}$. Average annual precipitation is $7,000 \mathrm{~mm}$, with variations according to adiabatic conditions that can generate storms with $80 \mathrm{~mm}$ precipitations in one day (Ibid). According to data from the 2005 National Census, the total population of the Municipality is 328,794 inhabitants; 292,947 of which occupy the urban area and 35,847 the rural sector ${ }^{30}$. The population mainly comprises Afro-American descendants and indigenous populations and a small proportion of colonists coming from the Departments of Antioquia, Caldas, and Risaralda (Ibid). Buenaventura is the main marine port of Colombia on the Pacific coast.

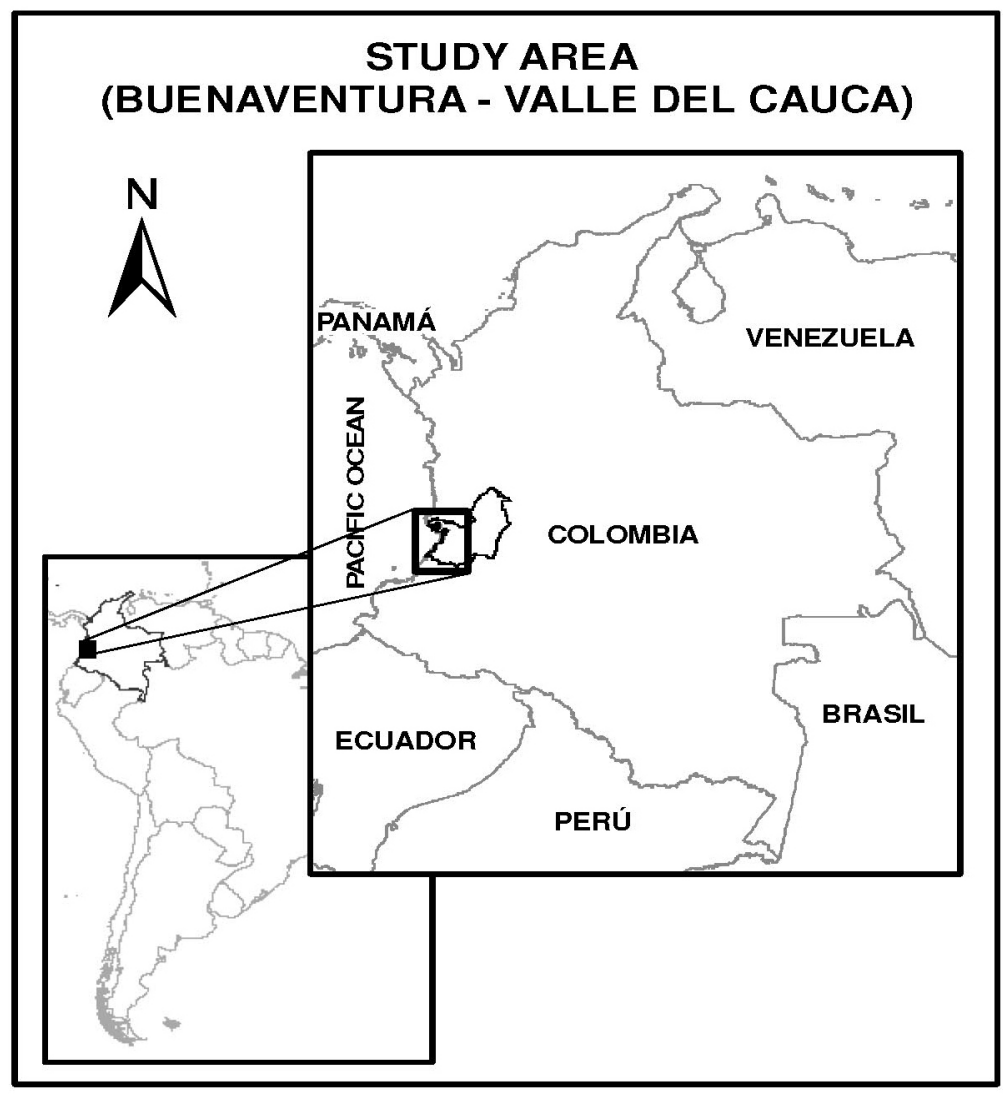

Figure 1 - Location of study area, Buenaventura - Colombia

Figura 1 - Localización del Área de Estudio, Buenaventura - Colombia. 
Model adaptation and input information

The model distribution of malaria formulated by Craig et al. ${ }^{1}$ for part of the African continent is adapted in this study. It consists of estimating the spatial distribution of the illness based on the influence of temperature and precipitation on the biological behavior of the parasite and mosquito transmitter. Although the model was designed for small scale studies (continent scale), it is adapted in both spatial and temporal resolution. It was also used because it involves spatial distributed environmental variables for a simple implementation. Thus, climatic convenience scenarios were built for the illness, applying a diffuse curve as a function of climatic variables using IDRISI ANDES 15.01 software from Clark Labs, Clark University, and pertaining Fuzzy Logic module. The required environmental input information for the model was provided by the Instituto de Hidrología, Meteorología y Estudios Ambientales de Colombia - IDEAM, furnishing daily data on precipitation, temperature, and relative humidity, for the stations located throughout the Colombian Pacific coast for the period from 1999 to 2005. Data from 96 stations were used: 78 stations measured precipitation and 18 measured temperature and relative humidity parameters.

Precipitation and temperature information was subjected to Data Exploratory Analysis (DEA), adopting techniques introduced by Carvajal ${ }^{31}$. This includes data quality evaluation, filling the gaps in the series, data error cleaning from different sources, and others, which were carried out using the SPSS-10.0 Statistical Package for the Social Sciences ${ }^{32}$.

Spatial distribution for environmental variables was carried out by using data approved via DEA once the series were completed. Climatic variable maps were generated adapting the methodology suggested by Leguizamón ${ }^{33}$, which establishes correlations between climatic variables and altitude. This method was previously introduced by Rincón-Romero ${ }^{29}$. The source of elevation information came from the digital elevation model (DEM) from the Shuttle Radar Topography Mission (SRTM) ${ }^{34}$, with pixel size of $30 \mathrm{~m}$. The tool used for spatial data analysis was ARCGIS $9.0^{35}$, with the module for spatial analysis. Thus, spatial distribution of temperature is expressed as a function of elevation with calculation of a vertical gradient for the Pacific region, based on 15 climatic stations on a monthly basis. The calculation of the vertical gradient for temperature was carried out with linear regression with a first-degree polynomial function that relates temperature $\left({ }^{\circ} \mathrm{C}\right)$ to altitude (masl); (temperature in the $\mathrm{Y}$ axis and elevation in the $\mathrm{X}$ axis). The function was $Y=-0.0031 X+25.926$, with $R^{2}=0.8738$. The result from this procedure was 12 maps of multi-annual monthly average temperature for the 1999-2005 period, one for each month.

Precipitation and temperature variables were spatially distributed by grouping data monthly. The stations selected were those approved by the DEA process. A quarter-degree polynomial linear regression function was defined to relate precipitation $(\mathrm{mm})$ with altitude (masl); (Precipitation in the $\mathrm{Y}$ axis and elevation in the $\mathrm{X}$ axis). The function was: $\mathrm{Y}=1 \mathrm{e}^{-9} \mathrm{X}^{4}+4.2 \mathrm{e}^{-6} \mathrm{X}^{3}-6.5 \mathrm{e}^{-3} \mathrm{X}^{2}+3.5 \mathrm{X}+$ 384.68; $\mathrm{R}^{2}=0.79$, where: $\mathrm{Y}=$ calculated value of accumulated precipitation, $X=$ Value of elevation (In this case the DEM is used).

The thresholds for environmental variables were adjusted for the Colombian Pacific coast, since almost all cases of malaria were produced by $P$. vivax and $P$. falciparum parasites, for which environmental conditions influence on the biological aspects of parasites. This adjustment was conducted according to the proposal by Londoño ${ }^{36}$, and values are presented in Table 1.

\section{Model application}

The application of the model was conducted in the three instances mentioned, as illustrated in the diagram in Figure 2. This outline gives the operative sequence of organization of the data used in the process, the spatial distribution process for environmen- 
Table 1 - Spatial variables used in the model.

Tabela 1 - Variables espaciales usadas en el modelo

\begin{tabular}{|c|c|c|c|c|}
\hline \multirow{2}{*}{$\begin{array}{l}\text { Spatial Index or } \\
\text { variable }\end{array}$} & \multirow[b]{2}{*}{ Description } & \multirow[b]{2}{*}{ Input data } & \multicolumn{2}{|c|}{ Range of values } \\
\hline & & & Convenience & No convenience \\
\hline Precipitation & $\begin{array}{l}\text { Spatial distribution of } \\
\text { mean annual rainfall }\end{array}$ & $\begin{array}{c}\text { Weather station data } \\
\text { and DTM }\end{array}$ & $\begin{array}{c}350 \mathrm{~mm} \text { annual }<\mathrm{X}< \\
950 \mathrm{~mm} \text { annual }\end{array}$ & Out of range \\
\hline Temperature & $\begin{array}{c}\text { Spatial distribution of } \\
\text { mean annual temperature }\end{array}$ & $\begin{array}{c}\text { Weather station data } \\
\text { and DTM }\end{array}$ & $18^{\circ} \mathrm{C}<\mathrm{X}<40^{\circ} \mathrm{C}$ & Out of range \\
\hline $\begin{array}{l}\mathrm{MCCl} \\
\text { Malaria Climatic } \\
\text { Convenience Index }\end{array}$ & Values between 0 - 1 & $\begin{array}{c}\text { Spatially } \\
\text { Precipitation and } \\
\text { temperature }\end{array}$ & $\begin{array}{l}\text { Normalized value } \\
1 \text { or near to } 1\end{array}$ & $\begin{array}{l}\text { Normalized value } \\
0 \text { or near to } 0\end{array}$ \\
\hline $\begin{array}{l}\text { DDNF } \\
\text { Distance to Drainage } \\
\text { Network for Flooding - } \\
\end{array}$ & $\begin{array}{l}\text { Euclidean distance from } \\
\text { drainage network }\end{array}$ & $\begin{array}{l}\text { Spatial drainage } \\
\text { network }\end{array}$ & $\begin{array}{l}\text { Om. Euclidean } \\
\text { distance }\end{array}$ & $\begin{array}{l}\text { 3500m. Euclidean } \\
\text { distance }\end{array}$ \\
\hline $\begin{array}{l}\text { SSP } \\
\text { Suitable slope for } \\
\text { pooling } \\
\end{array}$ & $\begin{array}{l}\text { Almost flat areas with } \\
\text { very small slope for } \\
\text { pooling }\end{array}$ & DTM & $\begin{array}{c}\text { Between } 0 \text { to } 10 \\
\text { degrees of inclination }\end{array}$ & $\begin{array}{c}\text { More than } 10 \\
\text { degrees of inclination }\end{array}$ \\
\hline $\begin{array}{l}\mathrm{MGCl} \\
\text { Malaria } \\
\text { Geomorphologic } \\
\text { Conditions Index } \\
\end{array}$ & $\begin{array}{l}\text { Landscape physical } \\
\text { conditions appropriate } \\
\text { form malaria }\end{array}$ & DDNF，SSP & $\begin{array}{l}\text { Normalized value } \\
1 \text { or near to } 1\end{array}$ & $\begin{array}{l}\text { Normalized value } \\
0 \text { or near to } 0\end{array}$ \\
\hline $\begin{array}{l}\mathrm{MNCl} \\
\text { Malaria Natural } \\
\text { Convenience Index }\end{array}$ & $\begin{array}{c}\text { Physical natural } \\
\text { conditions appropriate } \\
\text { form malaria from climate } \\
\text { and landscape }\end{array}$ & $\mathrm{MGCl}, \mathrm{MCCl}$ & $\begin{array}{l}\text { Normalized value } \\
1 \text { or near to } 1\end{array}$ & $\begin{array}{l}\text { Normalized value } \\
0 \text { or near to } 0\end{array}$ \\
\hline $\begin{array}{l}\text { DRA } \\
\text { Distances to Roads of } \\
\text { Access }\end{array}$ & $\begin{array}{c}\text { Euclidean distance } \\
\text { to road for access for } \\
\text { mobilization }\end{array}$ & Spatial data of roads & $\begin{array}{l}\text { Om Euclidean } \\
\text { distance }\end{array}$ & $\begin{array}{l}\text { 60000m Euclidean } \\
\text { distance }\end{array}$ \\
\hline $\begin{array}{l}\text { Distances to towns } \\
\text { - DT }\end{array}$ & $\begin{array}{l}\text { Euclidean distance to } \\
\text { towns and communities }\end{array}$ & $\begin{array}{c}\text { Spatial location of } \\
\text { main towns of study } \\
\text { area }\end{array}$ & $\begin{array}{l}\text { Om Euclidean } \\
\text { distance }\end{array}$ & $\begin{array}{l}\text { 20000m Euclidean } \\
\text { distance }\end{array}$ \\
\hline $\begin{array}{l}\text { Accessibility Distance } \\
\text { to Water - ADW }\end{array}$ & $\begin{array}{l}\text { Euclidean distance to } \\
\text { water source for human } \\
\text { consumption }\end{array}$ & $\begin{array}{l}\text { Spatial data of } \\
\text { Main river network }\end{array}$ & $\begin{array}{l}\text { Om Euclidean } \\
\text { distance }\end{array}$ & $\begin{array}{l}\text { 1000m Euclidean } \\
\text { distance }\end{array}$ \\
\hline $\begin{array}{l}\text { Suitable Slopes for } \\
\text { Living - SSL }\end{array}$ & $\begin{array}{c}\text { Areas with low slope for } \\
\text { house settlement }\end{array}$ & DTM & $\begin{array}{l}0 \text { degrees of } \\
\text { inclination }\end{array}$ & $\begin{array}{l}35 \text { or more degrees } \\
\text { of inclination }\end{array}$ \\
\hline $\begin{array}{l}\text { TOPI } \\
\text { The Territory } \\
\text { Occupation Preference } \\
\text { Index }\end{array}$ & $\begin{array}{c}\text { Suitable areas with more } \\
\text { amenities for house } \\
\text { settlement }\end{array}$ & SSL , ADW , DRA , DT & $\begin{array}{l}\text { Normalized value } \\
1 \text { or near to } 1\end{array}$ & $\begin{array}{l}\text { Normalized value } \\
0 \text { or near to } 0\end{array}$ \\
\hline MTRI & $\begin{array}{c}\text { Area with more } \\
\text { probability to contract } \\
\text { malaria }\end{array}$ & $\mathrm{MCCl}, \mathrm{MGCl}, \mathrm{TOPI}$ & $\begin{array}{l}\text { Normalized value } \\
1 \text { or near to } 1\end{array}$ & $\begin{array}{l}\text { Normalized value } \\
0 \text { or near to } 0\end{array}$ \\
\hline
\end{tabular}

tal variables, and the whole algebra with raster maps used in the generation of the required space data. Finally, the proposed indicators were set to reach the risk index for malaria infection. The model operation is a simple algebraic map handling spatial data distribution. The logic is based on the spatial occurrence or existence of an event and its topological relationship evaluated as a Euclidean distance index or proximity. The results show the location of the exposed element (the human being) within a range of actions or people affected as per the evaluated variable. The same weight was 
assumed for all variables, because there is no evidence that for this analysis and this scenario one is more important than others. By identifying the prevalence or the potential exposure of human beings to acquire the illness, parameters or action ranges were evaluated and limited according to common sense. Adjustments were made when one of them was more physically obvious than the others (Table 1). The expressed real values were normalized between zero and one (0-1) and stored in the pixels of the models for all the variables used. Thus, the pixels that took the value of one (1) and the nearest to one show the sites in which it is more likely to acquire the illness. On the other hand, zero and nearest to zero values represent the sites that should offer lower risks of acquiring the illness. These values were distributed by using a fussy logic decreasing Sigmoidal-type curve, adopting the limits of appropriate or inappropriate con- ditions defined for that purpose (Table 1). Once the values were spatially distributed on the study area for each of the variables, the algebraic map treatment was carried out, as represented in the diagram in Figure 2 , which shows the operative design for the proposed model. All algebraic processes with maps were carried out with ArcGIS $9.1^{35}$. The maps that are not included in this paper due to volume can be requested from the authors directly by email.

Variables included in the model were:

- Malaria Climatic Convenience IndexMCCI: Precipitation and temperature convenience scenarios were calculated for every month (total of 24 images, one by month), using the parameters proposed by Craig et al. ${ }^{1}$ and the thresholds used for the study area. A new image was generated every month, creating an arithmetic mean between the two climatic data.

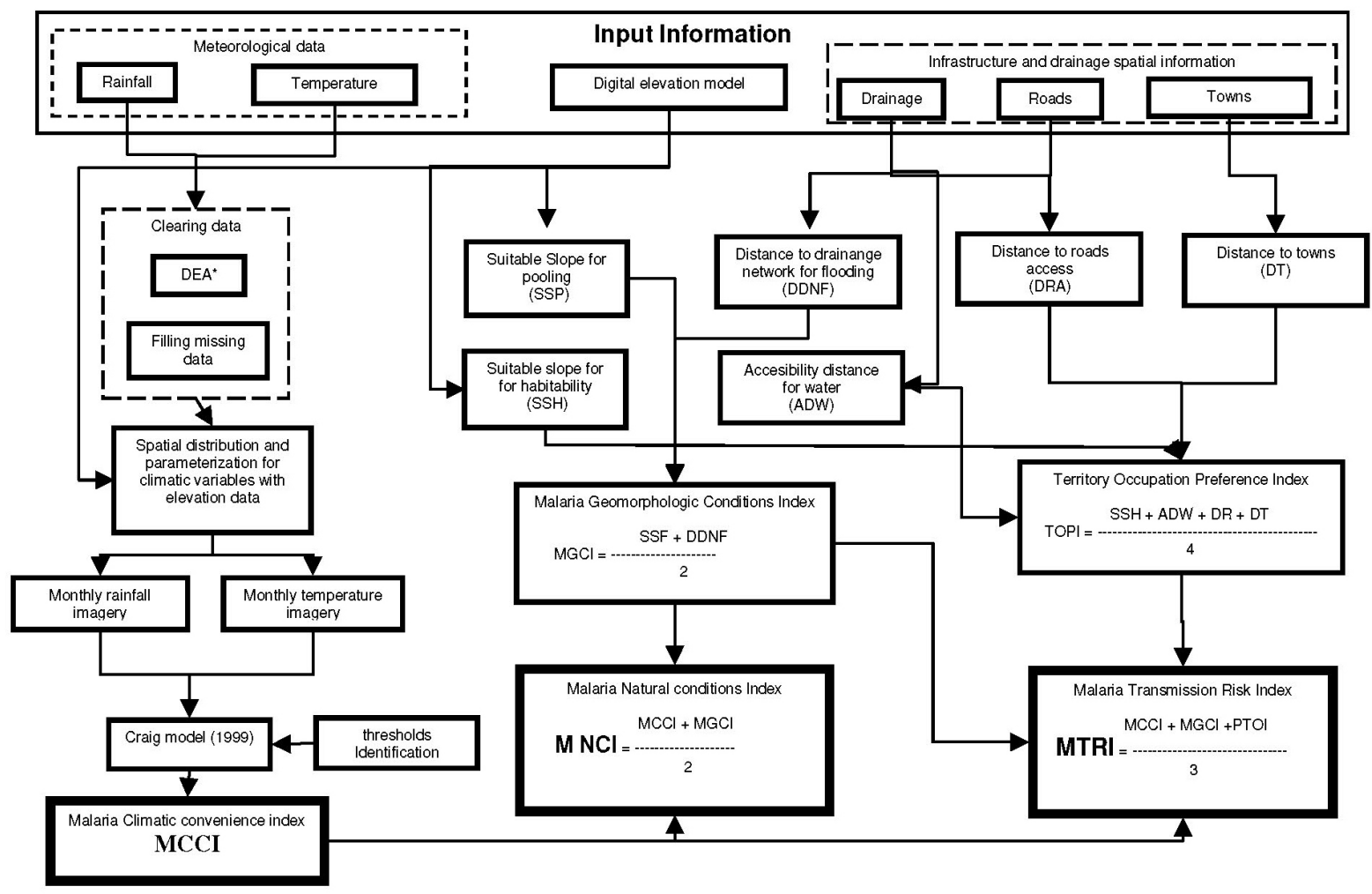

* Data Exploratory Analysis

Figure 2 - Diagram of Malaria transmission risk model.

Figura 2 - Diagrama del modelo de riesgo de transmisión de malaria. 
- Malaria Natural Convenience IndexMNCI: In addition to the ones proposed by Craig et al. ${ }^{1}$, other natural variables were included at a larger geographical scale. The variables were selected taking into account their spatial relevance for analysis in the procedure to map malaria affected zones. All cartographic data (network rivers, roads, town) were provided by the CVC (Corporación Valle del Cauca - regional environmental institution) in a 1:50,000 scale. Derived spatial variables were distance to rivers (Euclidean distance to drainage network for flooding - DDNF) and slopes of the land surface (Suitable slope for pooling - SSP) (Table 1); both broadly highlighted in literature from the point of view of convenience for vector proliferation ${ }^{8,9}$. These can also be included by logic, because - first of all - there are natural features related to the proliferation of mosquito hatcheries, and secondly, availability of information offers the opportunity of increasing new parameters in the analysis to improve awareness of malaria behavior (in terms of scale, or information availability). These variables were thus considered:

$\checkmark$ Distance to drainage network for flood (DDNF). The Euclidean distance index was calculated for drainages, from drainage network information, as a variable that impacts the creation of hatcheries of mosquitoes due to the possibility of water stagnation in areas nearest to the rivers. The limits adopted for appropriate or inappropriate conditions for water stagnation were a value of $0 \mathrm{~m}$ as the most appropriate condition that was assigned as value one (1) and areas with a distance of $3,500 \mathrm{~m}$, which were defined as an inappropriate condition and assigned as value zero (0). Intermediate values were assigned for distance to rivers. Some authors propose a $2 \mathrm{~km}$ distance to rivers $^{8}$ that can be associated with malaria. Although the landscape area is within mountains, authors tend to enlarge the relevant distance.

$\checkmark$ Suitable slope for pooling - (SSP). To supplement the influence of the previous variable, the slope was used as a decisive factor of water stagnates. This is because in areas with low slopes, water tends to be dammed because of physical soil properties ${ }^{29}$. Also, being close to hydrological sources involves permeability conditions and retention of riverside floors. With this in mind, limits of appropriate or inappropriate conditions were defined in slope terms. Selected value ranges from 0 to 10 degrees of slope inclination were considered as appropriate conditions for water stagnation, and other values as inappropriate (Table 1).

Both, DDNF and SSP were generated for the Malaria Geomorphologic Conditions Index (MGCI), which is calculated as an arithmetic mean of the previous indexes. The MNCI is calculated as the arithmetic mean of the index images of the MCCI and MGCI. In this first approach to the adaptation of the African model, natural scenarios were built including temperature, precipitation, DDNF, and SSP. The MNCI contains natural conditions that cause the presence of the malaria transmitter vector. Natural variables were combined showing the places where they coincide in location with geomorphologic features that can propitiate conditions for vector proliferation, elements in which the human being does not have effects.

In addition to these natural aspects that help vector proliferation, four aspects are added in this proposal that can help explain the presence of humans in particular places and their exposure to the potential presence of the vector. They are included in the Malaria Transmission Risk Index - MTRI. Based on the natural conditions of the territory, there are areas that offer people better living options than others, leading us to assume that people prefer to choose the place to live in terms of probability of being affected or not. In this study, this idea is expressed in an index called Territory Occupation Preference Index 
(TOPI). The TOPI shows the probability of territory occupation in terms of anthropicenvironmental variables, presenting hypothetical conditions in the place selected to settle, due to its suitable conditions for human activities, while there are places where people are exposed to malaria infection. To express this index, the elevation in spatial information was used to derive land slope surface and drainage network as criteria of proximity to access to water and important landscape amenities that environmental conditions offer to allocate housing. For this purpose, spatial information, such as road infrastructure and populated centers, was combined. Their proximity offers some comfort as criteria for selecting a place to live and therefore become decisive approaches. These last two variables were classified as anthropogenic variables, since they are generated on the natural landscape by man. Thus, the approach used sets out to evaluate which aspects are to be kept in mind when locating housing. These offer some comfort, amenity, or improve the well-being of the community. They were evaluated in terms of proximity (Euclidian distance) to these features. Additionally, spatial propagation of malaria transmission advances with the development of new human establishments. Those that regularly present poor infrastructure conditions $s^{30}$, particularly for these regions of the country, reveal greater incidence.

Criteria taken into account in the TOPI construction were:

- proximity to transportation roads and infrastructure for mobility (Distances to Roads of Access - DRA),

- proximity to populated centers, health centers, and schools (Distances to towns - DT),

- proximity to sources of water (Accessibility Distance to Water - ADW), and

- slope of the land, where selection of areas of lower slope were used for housing construction (Suitable Slopes for Habitability - SSH).

Based on spatial behavior variables, appropriate or inappropriate habitability con- ditions were theoretically defined (Table 1). These variables were calculated as follows:

$\checkmark$ Distance to the Roads of Access (DRA): For the municipality of Buenaventura, transportation roads such as highways (paved and affirmed roads) were taken into account, along with the main drainage network. Regarding transportation roads, appropriate or inappropriate habitability condition was established in terms of Euclidian distance to infrastructure. When the distance from the road or from the river is short, the probability of finding a community is greater. This index is comprised of the ADW and has threshold $0 \mathrm{~m}$ starting from rivers as an appropriate condition, and $4,000 \mathrm{~m}$ as an inappropriate condition. The index of Proximity to Roads (DRA) adopts $0 \mathrm{~m}$ starting from roads as an appropriate condition, and $60,000 \mathrm{~m}$ as an inappropriate condition. The latter value was adopted because the whole area has to have the possibility to be inhabited.

$\checkmark$ Accessibility distance for Water (ADW): A condition for the selection of a site for housing is the availability of water for human consumption. Proximity to a water source is included in the model as a variable according to the Euclidean distance, where the adapted condition is $0 \mathrm{~m}$ to $4 \mathrm{~km}$ from sources of water. Larger distances were not contemplated as appropriate conditions.

$\checkmark$ Distances to Towns (DT): Populated centers, health centers, and schools are considered as Infrastructure variables, since they are the places that can congregate the nearest community and share spaces with people that might be infected with malaria. As the previous variable, DT uses Infrastructure as appropriate or inappropriate habitability conditions in terms of distance. The shorter the Euclidean distance to infrastructure, the more likely to find human settlements. Hence, $0 \mathrm{~m}$ is adopted as starting from the roads as an appropriate condition with an assigned value 1 , and ending with $20,000 \mathrm{~m}$ as an inappropriate con- 
dition with assigned value 0 .

$\checkmark$ Suitable Slope for Habitability (SSH): The slope was considered in this context as an anthropic factor, because it is interpreted as a key factor in the decision to create a new human settlement. Most of man's activities are carried out in low slopes up to moderate inclinations. Slope limits were defined for appropriate or inappropriate conditions, where inclination values between 0 to 35 degrees were set as appropriate slope conditions for habitability, and larger slopes were inappropriate conditions for the development of human activities.

The Territory Occupation Preference Index (TOPI) is calculated by the algebraic means of the previous indexes by using GIS tools: $\mathrm{TOPI}=(\mathrm{SSH}+\mathrm{ADW}+\mathrm{DRA}+\mathrm{DT}) /$ 4. The result is the spatial convenience or space preference for living, considered as an anthropic aspect, which is expressed in values from 0 to 1 , where 0 is the most inconvenient value, and 1 represents the most convenient conditions for living or allocation of a place to live. No different weights were assigned because there is no existing measured evidence that support the differentiation.

Finally, in the MTRI it is clear that for vector proliferation there is no evidence of which variable is more preponderant over the others. As a consequence, all variables will have the same weight within the spatial algebraic process. On the other hand, there is the selection of variables to define the risk of being contagious. In order to identify the risk, three groups of variables were built: climatic, morphological, and anthropogenic variables. Each group of variables was assigned the same weight in the definition of risk to acquire malaria. The proposed calculation is MTRI $=(\mathrm{MCCI}+\mathrm{MGCI}+\mathrm{TOPI})$ / 3. The final risk map is shown in the results section (Figure 4).

\section{Results and analysis}

For the municipality of Buenaventura-
Colombia, six years of meteorological data were received from 50 stations of the 96 used, showing a very marked rainy season for August, September, and December, and stronger rains in April and May; and less rain for the months of January, February, and March.

According to the analysis of mean monthly values, the minimum value of rain was registered at $78.4 \mathrm{~mm}$ for June and the maximum value was $125 \mathrm{~mm}$ in the same month. The registered mean monthly temperature value was $24.3^{\circ} \mathrm{C}$ with a variation ranging between 12.7 and $26^{\circ} \mathrm{C}$. This information determines that the temperature variable does not have significant influence within the used model. This means that the temperature in the region significantly favors the proliferation of the vector, but it does not vary given its constant behavior.

This study proposes the integration of spatial information to zone and represent spatial distribution of malaria on a cartographic medium scale for adapting the numerical model proposed by Craig et al. ${ }^{1}$ for malaria spatial distribution in the African continent. The model is based on climatic variability, particularly of rain and temperature conditions on the behavior of the weather that are favorable to the parasite and the vector transmitter, generating zones of climatic convenience for malaria creating the MCCI. The relationship between precipitation and altitude was derived from data of 24 series, from 35 approved by DEA, located in the North Pacific region. Precipitation images were generated and accumulated for every month on the basis of the relationship with altitude. The result from this procedure was 60 accumulated precipitation maps for the 2001-2005 period (corresponding to the period of readiness for malaria registrations) and 12 accumulated precipitation maps at level monthly average multi-annual and finally one more annual average multi-annual for the 1999-2005 period. In the same way temperature maps were built in order to support input data for MCCI. An aggregated map of MCCI is presented in Figure 3. Based on this information, geomorphologic 
information was combined and produced 12 scenarios of Natural Convenience for Malaria built at a multi-annual, monthly average for the (1999 - 2005) period of study and a scenario of multi-annual average, which led to the MNCI (Figure 3).

Adaptation of the Craig et al. ${ }^{1}$ model includes strategies of scale adjustments and the addition of new environmental and anthropic variables to highlight the space covered by the areas with the illness; and addition of natural physical variables and the spatial distribution of the population, generating a risk-transmission map of malaria. The work was developed by using Geographical Information Systems (GIS) tools at a 1:100,000 scale, applying modeling space methodologies, helping to identify, highlight, and remark those areas with more people affected by the illness; and showing their potential environmental suitability and risk of infection. The result is presented in Figure 4.

Regarding the indicators derived in this study, classification categories of the three indexes calculated (MCCI, MNCI, MTRI) were expressed initially with values betwe- en zero and one. Results were reclassified into four categories given empirically by convenience of their spatial representation in the maps, following a proposal presented by Snow et al. ${ }^{3}$, and are presented in Table 2.

Analyzing the classification from the Table 2, the very high class (of 0.75 to 1.0 ), of MCCI covers $71.5 \%$ of the study area; MNCI and MTRI cover up to $24.4 \%$ and $30.4 \%$, respectively, showing significant refinement in the area reported.

Despite climatologic data at daily temporary resolution being available, they were added to monthly scales to permit adapting the model by Craig et al. ${ }^{1}$ and to have elements of comparison to these results.

As the size of the study area was relatively small, the adopted spatial resolution of the pixel size (100m) compared to that proposed by Craig et al. ${ }^{1}(1 \mathrm{~km})$ was quite different. In consequence, the scale differences in cartographic data used, and landscape type in each case are also different. The study area has climatic variability in both temporal and spatial resolution. Climate changes in small periods, basically in rainy conditions due to humid winds coming over the Pacific Ocean
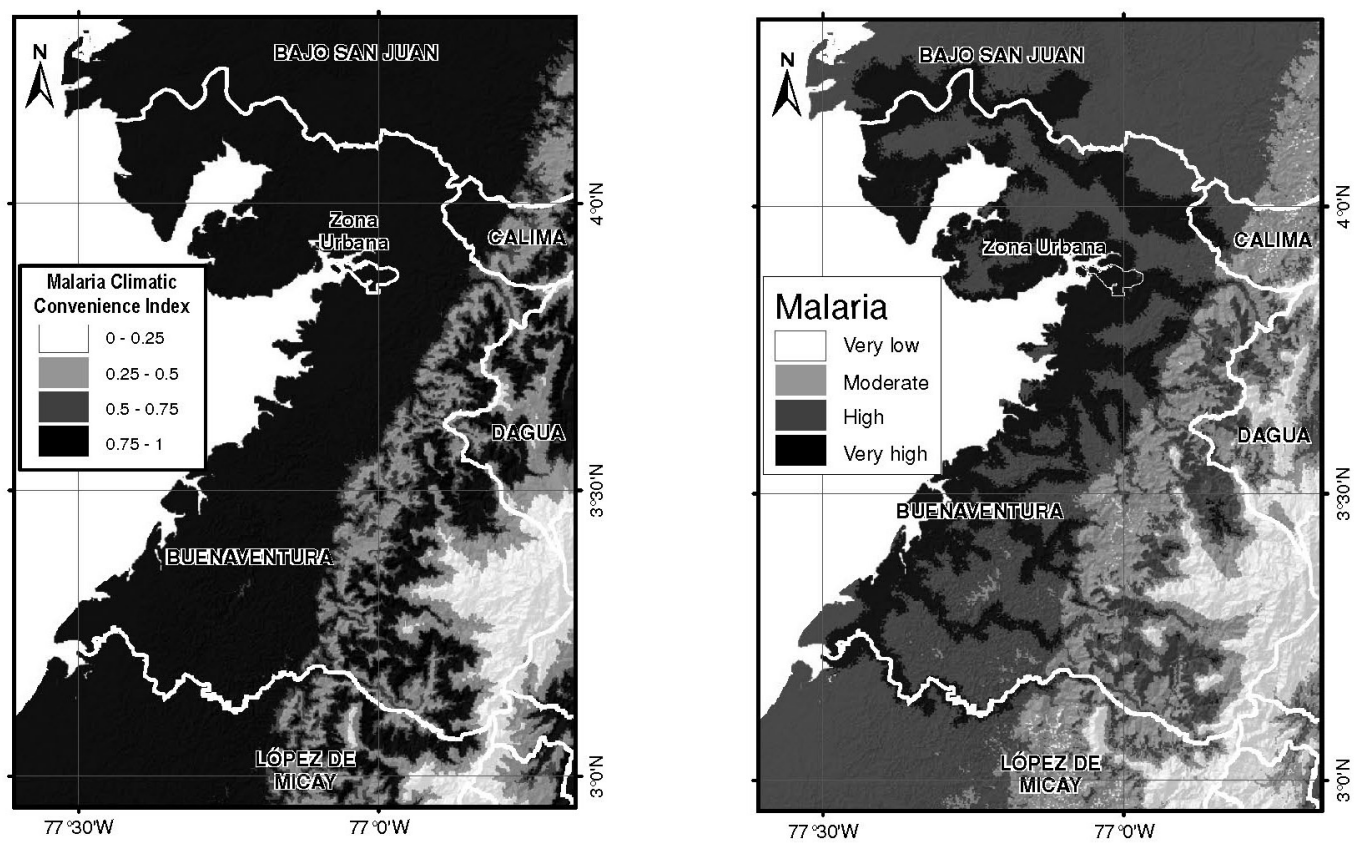

Figure 3 - Spatial distributed MCCI (left) and MNCI (right) indexes.

Figura 3 - Índices de distribución espacial de $\mathrm{MCCl}$ (izquierda) y $\mathrm{MNCl}$ (derecha). 


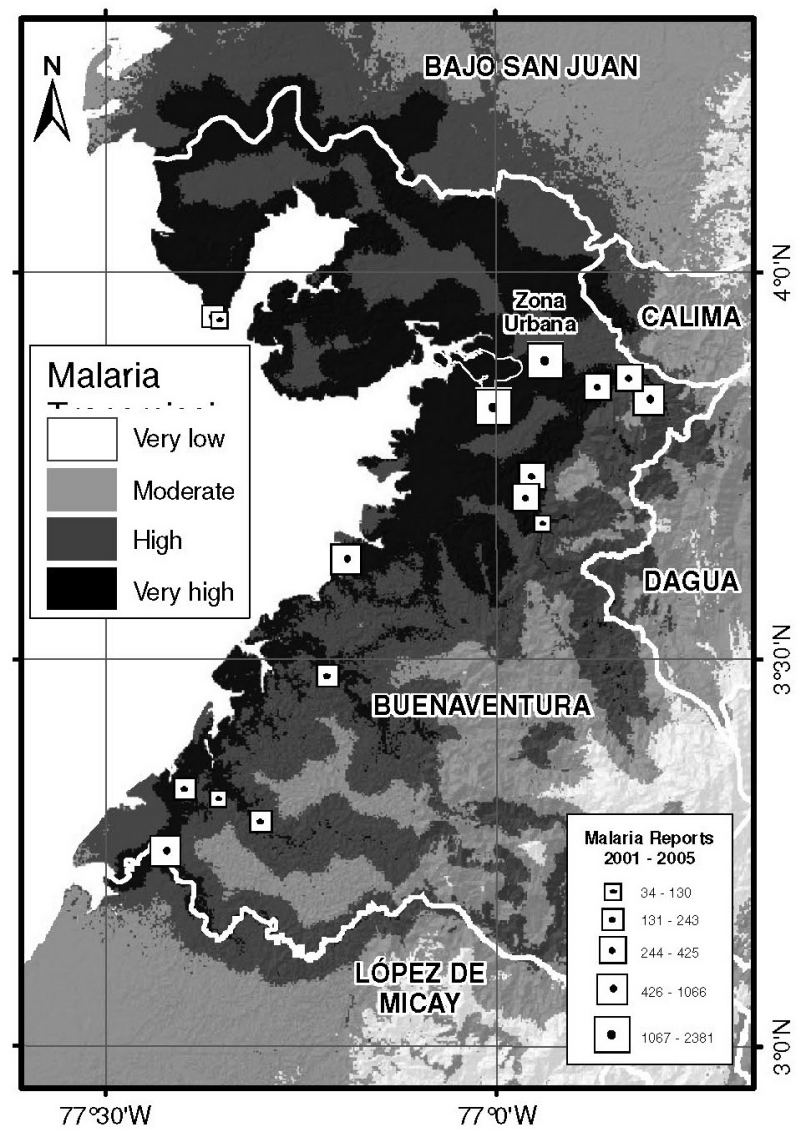

Figure 4 - Spatial distribution of MTRI.

Figura 4 - Distribución espacial del Índice MTRI.

Table 2 - Comparison of results between $\mathrm{MCCl}, \mathrm{MNCl}$, and MTRI

Tabela 2 - Comparación de resultados entre los Índices MCCI, MNCI y MTRI

\begin{tabular}{|c|c|c|c|c|c|c|}
\hline \multirow[b]{2}{*}{ Class } & \multicolumn{2}{|c|}{$\mathrm{MCCl}^{1}$} & \multicolumn{2}{|c|}{$\mathrm{MNCl}^{2}$} & \multicolumn{2}{|c|}{$\mathrm{MRTI}^{3}$} \\
\hline & Area $\mathrm{Km}^{2}$ & $\%$ & Area $\mathrm{Km}^{2}$ & $\%$ & Area $\mathrm{Km}^{2}$ & $\%$ \\
\hline Low & 489.8 & 8.1 & 643.7 & 10.6 & 457.9 & 7.5 \\
\hline Moderate & 895.5 & 14.7 & 1188.9 & 19.5 & 1319.4 & 21.7 \\
\hline High & 350.2 & 5.8 & 2767.0 & 45.5 & 2456.7 & 40.4 \\
\hline Very high & 4347.9 & 71.5 & 1493.9 & 24.4 & 1849.4 & 30.4 \\
\hline
\end{tabular}

' Malaria Climatic Convenience Index

${ }^{2}$ Malaria Natural Convenience Index

${ }^{3}$ Malaria Transmission Risk Index

and crashing to the high mountains on the coast. There are also changes in the space due to orographic conditions that in very short distances produce strong changes in elevation, and consequently in temperature, vegetation and landscape too. Based on this variability, and with the help of data with more resolution in both space and time, epidemics of the illness or the increment or decrease of the reported disease cases in the area may be identified.

The novel features of this model proposal are:

- it is not based only on environmental 
conditions like previous approaches;

- it uses greater spatial and temporal resolutions;

- it includes geomorphologic data as a natural variable that impacts on the conditions that affect mosquito proliferation, and

- it includes natural variables that are assessed as amenities to settles a community on a certain area.

This combination refines the model results from the first approach of the MCCI, that estimates an area of $5,422.4 \mathrm{~km}^{2}$ in its high class (see Table 2 ), compared with 624.3 $\mathrm{km}^{2}$ of the area in the MTRI for the same category. The zoning refinement from MCCI, MNCI and IRCM reduces the action areas, concentrating the zoning to those areas where rainwater stagnation occurs.

The inclusion of geomorphologic variables in both, natural conveniences for mosquito proliferation, and habitability preference conditions of a place to settle, make this approach refine the areas of high risk in $79 \%$, compared with areas described by the MCCI. This proposal reduces the area by $4,756 \mathrm{~km}^{2}$, focusing only on those areas with greater possibilities of having the illness; this becomes a decisive element for health entities that help to clearly identify where to develop mitigation campaigns and where to apply the scarce resources that can have a greater effectiveness index in the fight against the illness.

To compare the results obtained among each other (MCCI, MNCI, and MTRI), two types of analyses were carried out, one punctual and the other zonal. In the punctual analysis, three places were identified on the basis of information available, which reported the presence of the illness by health entities ${ }^{2}$. The more contrasted sites were the towns of Córdoba, Zacarias, and La Delfina. For the first two towns, the MCCI was very constant during every month of the year, which did not provide additional information to what was already known, while in La Delfina, malaria peaks were identified in February and August, which are related to its peculiar climatic conditions, where precipitation decreases to $660 \mathrm{~mm}$, and temperature increases during the same months. The elements associated with MNCI and MTRI were not evaluated, because population concentration in those sites does not reflect differences compared to other towns.

The spatial comparison of the three final indexes (MCCI, MNCI, and MTRI) is shown in Figures 3 and 4, including the reported cases of malaria, annually. They show with different magnitudes the places where infected people were reported, which may associate directly to the MTRI index. Results were contrasted spatially to data obtained from local health entities ${ }^{2}$. According to health data collected data between 2000 and 2005, the sites with more malaria reported cases are highlighted as the legend key presented on figure 4 . Spatial analysis shows $89 \%$ of reported cases were located in areas classified among Very High and Moderate classes, showing a great coincidence of the reported cases with the results obtained with the MTRI.

\section{Discussion}

The risk concept is regularly associated with the uncertainty or probability that a future event will occur within a certain period and given conditions, resulting in economic or social losses and with its eventual impact ${ }^{38}$. In other areas of knowledge like environmental studies, there are diverse methodologies to evaluate the risk. In this case, susceptibility of an individual is the first feature to evaluate, then vulnerability is associated with an event where the subject can be exposed to a threat; once the threat is consolidated, an eventual hazard could be generated which it is understood as risk.

Researchers have identified the importance to acknowledge in some extent where are the areas of high risk for acquiring malaria ${ }^{4-14}$, and they have included the use of techniques to manage spatial data with GIS and RS ${ }^{1,8-11}$, but those attempts have not always achieved more appropriate 
spatial representations to focus on the fight against malaria. It could be due to different circumstances (non-availability of spatial data, methodology of the data collection of the disease, ignorance of the precise spatial position of the people who have acquired the disease, among others). In consequence, approximations showing risk of acquiring malaria are presented in maps using choropleth with edges as administrative units, which limit the scope of information offered, and do not give the accurate spatial position of the high malaria risk. In addition to identifying environmental and climatic conditions $^{8,10,11}$, as the factors to associate to spread of vector and malaria parasite on a surface, there are other attempts to identify areas with malaria. Some authors have adopted the use of the Annual Parasite Index $\mathrm{API}^{7,13}$ for mapping Malaria risk, which has been expressed by the relation between number of positive blood cases and total population and represented by API.

Each of these approaches is valuable, and seek to identify areas with high risk of malaria transmission by adopting a concept of regarding the basic information used, or search space of neighborhood relations for the behavior of the disease ${ }^{12}$. But these efforts might not cover all possibilities, obviously due to the approach given by the researcher or by the limitation derived from inconsistencies of the available spatial information.

Also the concept of risk mapping could be misunderstood or confused with zoning of priority areas ${ }^{13}$ using choropleth maps. It is also known that within the same administrative unit boundary, variability in both environmental and climatic conditions can be quite large $\mathrm{e}^{7}$, which makes this approach very broad and widespread throughout the region $^{8,9,13}$. This might be very useful to cover very large areas. It is acknowledged that these approaches generate problems of borders, and have led researchers to take into account spatial relations of neighborhood. They also make use of other information such as economic, environmental or social aspects that relate geographical sites other than the boundaries of administrative divisions $^{9,12}$. On the other hand, large scale and resolution generate more detail information but the same quality of input data ${ }^{11}$ is also needed, as is the case of the study of Bautista et al. ${ }^{11}$, who carried out at micro-scale for the Peruvian Amazon area.

Using these bases, the concept of mapping risk of malaria transmission adopted here is built spatially, distributed as a product of spatial combination of natural and anthropic variables, which were assessed under adopted parameters (Table 1) for the study area and the scale of the analysis.

The application of the model proposed by Craig et al. ${ }^{1}$ was designed to a continental scale, that produces the waited results in the zoning of the malaria climatic convenience. In the case of this model result for Buenaventura-Colombia, it covers almost the whole municipality area with the maximum condition of malaria climatic convenience index (Figure 3). In contrast, the map of MTRI reduces this area in $4,756 \mathrm{~km}^{2}$, with only $10 \%$ of the municipality area with more potential risk offered according to proposed conditions. This shows that in order to get better results, not only information with more spatial density is needed, but their treatment must be carried out at a greater spatial scale, moreover when the landscape characteristics of the study area are so heterogeneous, and with high spatial variability in reduced areas, as it is the case of the municipality of Buenaventura-Colombia.

In this sense, the utilization of GIS tools is of vital importance in epidemiological studies, given their capacity of spatial analysis, broadly discussed through the literature ${ }^{1,8-13,18,20}$. Equally, it is important to identify the most appropriate mathematical procedure to apply according to the study area, as well as the use of available information and their spatial distribution over the study area, because wrong procedures may incur in erroneous conclusions and in consequence false results, facts discussed thoroughly by Brooket et al. ${ }^{39}$. As this proposal implements a simple spatial numerical analysis, it shows that is not imperative to 
use a very sophisticated mathematical spatial distributed model in order to improve the knowledge on the spatial distribution of malaria. In some of the complex mathematical models, results could show differences between algorithms instead of actual illness conditions.

Although most of the studies reviewed concentrate on the relationship between environmental variables ${ }^{1,8,10}$ and the living conditions of the parasite and the presence of the illness throughout the API ${ }^{13}$; this approach demonstrates the need to include other variables of the landscape that equally are related to malaria. Additional variables suggested are:

- the presence and location of human being in certain regions;

- the characteristics of human behavior ${ }^{9}$, including conditions of preference for settling housing, and relationship with landscape;

- landscape characteristics ${ }^{9}$ such as geomorphologic features, land cover, among others.

Topics like population's mobility, land use and cover change, deforested areas related to mosquito's breeding, or API are not discussed in this work due to non-availability of data. However these are variables that should undoubtedly equally be included in this type of approaches. In addition to the mosquito as a transmitter agent of the illness, human beings can equally transport the illness, and their behavior can influence mobility of malaria and its spatial distribution.

Regarding the study scale, it is evident that if we contrast the results of this study with those coming from large areas (small scale) of general studies ${ }^{1,11-13,22,40,}$ that report cartography at country or continent level, they will show obvious differences. The scale comparison indicates that it is necessary to improve the level of studies, in order to focus on measures of prevention and mitigation against the illness, in order not to apply the scarce resources to a big general area and focus more resources on places where malaria is clearly identified.

With the help of GIS tools, spatial analysis becomes more reliable ${ }^{1,7-13}$, but results from processes that use a spatial interpolation approach also could produce misunderstandings ${ }^{7,11}$, because landscape has spatial conditions which offer different aspects that could modify the spatial location of the human being, such as rivers, roads, local fauna, geographic accidents among others $^{8}$. This makes malaria epidemiology very complex. Some help to overcome or reduce the spatial interpolation effects at the local scale is to include geomorphologic variables within the analysis, which involves landscape variability ${ }^{9}$ as a part of the model.

Here the MRTI is compared with reported infection cases ${ }^{2}$ that were the available information for the proper places; $89 \%$ of cases were located in areas with a MRTI greater than a 0.5 value. Unfortunately more detail information on the sick population was not available, such as API for the study area.

Using the Craig et al. ${ }^{1}$ model without any other variable is very general for big scale studies and in particular not sensitive for very humid and heterogeneous landscape like Buenaventura Colombia.

Still more research needs to be done in the sense of mapping malaria risk where approaches could be integrated with better resolution in space and time to produce valuable information to support decisions against the illness, parasite and vector. GIS spatial analysis seems to be a the best way to support approaches for mapping malaria risk. 


\section{References}

1. Craig MH, Snow RW, Sueur D le. A climate-based Distribution Model of Malaria Transmission in SubSaharan Africa. Parasitology Today 1999; 15(3); 105-111.

2. Datos de archivo de la Secretaria de Salud Pública de la Gobernación del Valle del Cauca.

3. Snow RW, Gouws E, Omumbo J, Rapuoda B, Craig $\mathrm{MH}$, Tanser CF et al. Models to predict the intensity of Plasmodium falciparum transmission: applications to the burden of disease in Kenya. Tran R Soc Trop Med Hyg 1998; 92: 601-6.

4. Kleinschmidt I, Bagayoko M, Clarke G et al. A spatial statistical approach to malaria mapping. Int J Epidemiology 2000; 29: 355-361.

5. Thomas CJ, Lindsay SW. Local-scale variation in malaria infection amongst rural Gambian Children estimated by satellite remote sensing. Tran R Soc Trop Med Hyg 2000; 94: 159-63.

6. Kleinschmidt I, Omumbo J, Briet O et al. An empirical malaria distribution map for West Africa. Trop Med Int Health 2001; 6: 779-86.

7. Souza-Santos R, VG de Oliveira M, Escobar AL, Ventura Santoso R, EA Coimbra Jr C. Spatial heterogeneity of malaria in Indian reserves of Southwestern Amazonia, Brazil. Int J Health Geog 2008: 7-55.

8. Zeilhofer P, Soares dos Santos E., Ribeiro ALM., Miyazaki RD, Atanaka dos Santos M. Habitat suitability mapping of Anopheles darling in the surroundings of the Manso hydropower plant reservoir, Mato Grosso, Central Brazil. Int J Health Geog 2007: 6-7.

9. Achee N, Grieco JP, Masuoka P, Andre R et al. Use of Remote Sensing and Geographic Information Systems to Predict Locations of Anopheles darling-Positive Breeding Sites Within the Sibun River in Belize, Central America. J Med Entomol 2006: 43(2): 382-92.

10. Hay SI, Snow RW, Rogers DJ. From Predicting Mosquito Habitat to Malaria Seasons Using Remotely Sensed Data: Practice, Problems and Perspectives. Parasitol Today 1998: 14(8): 306-13.

11. Bautista, C T, Chan AT, Ryan JR, Calampa C, Roper MH, Hightower AW, Magill AJ. Epidemiology and Spatial Analysis of Malaria in the Northern Peruvian Amazon. Am J Trop Hyg 2006: 76(6): 1216-22.

12. Gemperli A, Vounatsou P, Sogoba N, Smith T. Malaria Mapping Using Transmission Models: Application to Survey Data from Mali. J Epidemiol 2006; 163(3): 289-97.

13. Atanaka-Santos M, Souza-Santos R, Czeresnia D. Spatial analysis for stratification of priority malaria control áreas, Mato Grosso State, Brazil. Cad Saúde Pública 2007: 23(5): 1009 -12.
14. Instituto Geográfico Agustín Codazzi (IGAC). Principios Básicos de Cartografía Temática. Edición y publicación del IGAC, Bogotá Colombia. ISBN 958-9067-32-8; 1998.

15. Gatton M, Kelly-Hope L, Kay B, Ryan P. Spatial-temporal Analysis of Ross virus disease pattern in Queenland, Australia. Am J Trop Hyg 2004; 71(5): 629-35.

16. Ceccato P, Ghebremeskel T, Jaiteh M, Graves PM, Levy M, Ghebreselassie S, Ogbamariam A et al. Malaria Stratification, Climate and Epidemic Early Warning in Eritrea. Am J Trop Med Hyg 2007; 77(S6): 61-8.

17. Minakawa N, Munga S, Atieli F, Mushinzimana E, Zhou G, Githeko A, Yan G. Spatial distribution of anophelline larval habitats in Western Kenyan Highlands: effects of land cover types and topography. Am J Trop Hyg 2005; 73(1): 157-65.

18. Mapping Malaria Risk in Africa - Atlas of Malaria for Africa. MARA, 1999. Available online in http://www. mara.org.za [Accessed on May 2009].

19. Levine R, Peterson T, Benedict M. Geographic and ecologic distributions of the Anopheles Gambiae complex predicted using a genetic algorithm. Am J Trop Hyg 2004; 70(2): 105-9.

20. Malakooli MA, Biomndo K, Shanks GD. Reemergence of epidemic malaria in the hignland of western Kenya. Emerg Infects Dis 1998; 4: 671-6.

21. Lindsay SW, Martens WJ. Malaria in the African highlands: past, present and future. Bull World Health Organ 1998; 76: 33-45.

22. Diggle P, Moyeed R, Mowlinson B et al. Childhood malaria in the Gambia: a case-study in model-bases geoestatistics. Appl Stat 2002; 51; 493-506.

23. Thomson M, Connor S, D'Alessandro U et al. Predicting malaria infection in Gambian children from satellite data and bednet use surveys: the importance of spatial correlation in the interpretation of results. Am J Trop Med Hyg 1999; 61: 1-8.

24. Olano V, Carrasquilla G, Méndez F. Transmisión de la malaria urbana en Buenaventura, Colombia: aspectos entomológicos. Rev Panam Salud Publica/Pan Am J Public Health 1997; 1(4).

25. Poveda G, Graham NE, Epstein PR, Rojas W, Quiñones ML, Véldez ID et al. Climate and ENSO variability associated with vectorborne diseases in Colombia. En: Poveda G, Graham NE, Epstein PR, Rojas W, Quiñones ML, Véldez ID, Martens W (eds.). El Niño and the southern oscillation, multiscale variability and global and regional impacts. Primera Edición. Londres: Prensa de la Universidad de Cambridge; 2000.

26. World Health Organization. Roll Back Malaria Department - Basic Facts on malaria. Sin más información 2004. Available Online: http://www.who. int/en/index.html 
27. World Health Organization. Guidelines for the treatment of malaria. Suiza. 266p. ISBN 978924 154694; 2006. Available online in http:/ / www.who.int/en/index.html [Accessed on May 2008].

28. Pan American Health Organization. Status of Malaria Programs in the Americas: XLV Report. 1998; Available online in http://www.165.158.1.110/english/hcp/hctmala.htm [Accessed on May 2008].

29. Rincón-Romero ME. Modeling the Hydrological Sensitivity to Land Use Change in a Tropical Mountainous Environment [Doctoral Thesis]. Department of Geography, King's College London: University of London, UK; 2001.

30. DANE - Departamento Administrativo Nacional de Estadística. Censo Nacional 2005. Available Online in http://www.dane.gov.co/censo/ [Accessed on May 2009].

31. Carvajal Y, Barrios AF, Castro LM. Análisis cluster como técnica de análisis exploratorio de registros múltiples. Universidad del Valle; 2006 (In press).

32. SPSS. Statistical Package for the Social Science 2008. Available online in www.spss.com [Accessed on May 2008].

33. Leguizamón BA. Modelos Geoespaciales de la Distribución de Variables Climatológicas en el Territorio Colombiano [Tesis de Maestría]. Bogotá: Universidad Nacional de Colombia. Facultad de Ciencias. Departamento de geociencias. Programa de Postgrado en Meteorología; 2002.
34. Shuttle Radar Topography Mission (SRTM). Jet Propulsion Laboratory, California Institute of Technology; 2005. Available online in http://www2.jpl. nasa.gov [Accessed on January 2008].

35. ESRI. ArcGIS version 9.1. Redlands C. A. Environmental System Research Institute Inc. 2008.

36. Londoño JE. Zonificación del riesgo de malaria con base en la influencia de variables socio-ambientales: Caso de estudio Municipio de Buenaventura (Valle del Cauca - Colombia) [Disertación de pregrado en Ingeniería Topográfica]. Universidad del Valle: Colombia; 2008.

37. Solarte Y, González R, Hurtado JC, Alzate A. Influencia de la vegetación en la presencia, distribución y abundancia de criaderos de tres especies de Anopheles en la parte baja del Río Naya, Costa Pacifica Colombiana. Bol Mus Ent Univ Valle 1994; 2: 55-71.

38. Salcedo HE. Universidad del Valle. Curso Teoría y Análisis de los Desastres Naturales. Apuntes de Clase; 2004 (In press).

39. Brooker S, Clarke S, Kiambo-Njag J, Polark S, Mugo B, Estambale B, Muchiri E, Magnussen P, Cox J. Spatial clustering of malaria and associated risk factors during an epidemic in a highland area of western Kenya. Tropic Med Intern Health 2004; 9(9): 757-66.

40. Afrane Y, Zhou G, Lawson B, Githeko K, Yan G. Effects of microclimatic changes by deforestation on the survivorship and reproductive fitness of AOPHEES GAMBIAE in western Kenya highlands. Am J Trop Hyg 2006; 74(5): 772-8.

Recebido em: 16/12/08

Versão final reapresentada em: 15/04/09

Aprovado em: 23/06/09 